archives of thermodynamics

Vol. 36(2015), No. 3, 3-14

DOI: $10.1515 /$ aoter-2015-0018

\title{
Investigation of exhaust gas temperature distribution within a furnace of a stoker fired boiler as a function of its operating parameters
}

\author{
PIOTR KRAWCZYK* \\ KRZYSZTOF BADYDA \\ JACEK SZCZYGIEE \\ SZCZEPAN MEYNARZ
}

Division of Power Machines and Devices, Institute of Heat Engineering,

Warsaw University of Technology, Nowowiejska 21/25, 00-665 Warsaw, Poland

\begin{abstract}
Distribution of the exhaust gas temperature within the furnace of a grate boiler greatly depends on its operating parameters such as output. It has a considerably different character than temperature distributions in other types of boilers (with pulverised or fluidised bed), as it varies considerably across the chamber. Results presented in this paper have been obtained through research of a grate-fired hot water boiler with a nominal rating of some $30 \mathrm{MW}$. Measurements have been taken by introducing temperature sensors into prearranged openings placed in the boiler side walls. Investigation has been carried out for different output levels. Tests involved thermocouples in ceramic coating and aspirated thermocouples. The latter were used to eliminate influence of radiative heat transfer on measured results. Values obtained with both methods have been cross-checked.
\end{abstract}

Keywords: Exhaust gas temperature measurement; Grate boiler; Aspirated thermocouple

\section{Introduction}

Stoker fired boiler plants are common throughout Eastern Europe. The small- and mid-sized coal combustion plants utilize travelling grate stokers

${ }^{*}$ Corresponding Author. E-mail: piotr.krawczyk@itc.pw.edu.pl 
to produce steam or hot water that is used by district heating companies and industries.

In Poland within 272 heating utilities which operate heat generation systems with capacities exceeding $20 \mathrm{MW}$, there are 874 stoker fired hot water boilers [1]. Despite their considerable popularity in industrial applications, there are few published studies presenting results of measurements of exhaust gas parameters within the furnace. This knowledge is necessary to improve understanding of processes occurring during fuel combustion in this type of furnace, mainly in terms of searching opportunities for reducing harmful emissions, including those of $\mathrm{NO}_{x}$ and $\mathrm{CO}$ [2].

According to the generally accepted theory, in stoker boilers following processes occur from the place where the coal is fed to the moving grate: coal heating and drying, coal devolatilisation, ignition, char combustion and burn out [3,4]. Character of individual processes depends on the type of fuel (volatile matter content), as well as on boiler control. Consumption of fuels rich with volatile matter leads to a considerable temperature increase in the front part of the furnace, which may lead to intensive formation of nitrogen oxides. In order to prevent that it is necessary to aim at better equalisation of the exhaust gas temperature across the chamber through better distribution of air between the grate zones, and also between primary and secondary air flows. Of course the temperature distribution within the furnace is also affected by the furnace design, e.g., shape of the ignition arch. Angle of the front arch and its length affects the coal devolatilisation process [5].

This paper attempts to determine the temperature distribution within the furnace basing on temperature results obtained upon introducing temperature sensors into prearranged application openings on the side walls of a boiler. The tests have been performed for different boiler output levels. Both ceramic-coated and aspirated thermocouples were used. Neither output control methods nor air distribution used by the crew in normal operation were adjusted.

\section{Measurement of exhaust gas temperature distribution within a furnace}

Measuring flue gas temperature within a furnace of a solid fuel boiler is a difficult task due to harsh conditions - high temperature, often in excess of $1000{ }^{\circ} \mathrm{C}$, high dust content, chemically aggressive environment, as well as considerable dimensions of the chamber [5]. Nonetheless the fundamen- 
tal difficulty is due to the fact that every temperature sensor introduced into the furnace undergoes a heat transfer with its surroundings not only through convection, but also through radiation, which can considerably distort the measured results. For this reason alternative measurements methods have been developed, including optical methods (optical pyrometry) [7] or acoustic methods (acoustic pyrometry) [8-10]. An acoustic temperature field measurement (AGAM) is used in the boiler industry.

The acoustic method is based on the thermoacoustic phenomenon where the speed of acoustic wave propagation in gaseous environment depends on temperature. Acoustic-based measurement is an indirect method, as the directly measured value is time of propagation of an acoustic pulse from the signal emitter to the receiver. In order to determine temperature it is necessary to know chemical composition of the environment, i.e., concentration of exhaust gas components and their spatial distribution at the time of measurement. Unfortunately obtaining such information is not possible. Therefore following simplified assumptions need to be made to apply this method [6]:

- known and constant gas composition,

- homogeneous environment,

- straight-line trajectory of sound,

- thermodynamic properties of the exhaust gas, i.e. specific heat capacities independent of temperature (average values are used).

With these assumptions, acoustic method may also lead to inaccurate results. Other flaws of this method important in the context of this paper are high cost and necessity to adapt the boiler for measurements by enabling installation of signal transmitters and receivers on furnace walls.

For these reasons the testing process discussed below used:

- method based on introducing thermocouples into the furnace for longterm measurements (about 2 weeks),

- aspirated thermocouple for short-term verification measurements.

Thermocouples are widely used in measurements carried out within the furnace of power boilers (e.g., [7,11]).

Results presented in this paper have been obtained through research of a grate-fired hot water boiler with a nominal rating of some $30 \mathrm{MW}$ (Tab. 1). 
Table 1: Basic technical data of tested boiler.

\begin{tabular}{|l|c|}
\hline \multicolumn{1}{|c|}{ Parameter } & Value \\
\hline \hline Rated power & $29 \mathrm{MW}$ \\
\hline Efficiency & $85 \%$ \\
\hline Fuel type & Coal \\
\hline The calorific value of the fuel & $21 \mathrm{MJ} / \mathrm{kg}$ \\
\hline The temperature of exhaust gas for maximum power & $155 \pm 10^{\circ} \mathrm{C}$ \\
\hline Minimum temperature of feed water & $70^{\circ} \mathrm{C}$ \\
\hline The water flow for maximum power & $90.0 \mathrm{~kg} / \mathrm{s}$ \\
\hline
\end{tabular}

Of course the authors are fully aware that the measurements taken with thermocouples introduced into the furnace suffer from inaccuracy attributable to thermal radiation. In order to estimate magnitude of this error, also a flue gas temperature by siphoning out was made (with aspirated thermocouple).

\subsection{Carrying out of temperature measurements with ceramic-coated thermocouples}

In order to execute long-term measurements of exhaust gas temperature within the furnace, holes were made in the side walls of the boiler to enable introducing thermocouples with a diameter not exceeding $15 \mathrm{~mm}$ (including coating) into the furnace. Three equally spaced holes were made in each wall, approximately $2 \mathrm{~m}$ above the grate level. Thermocouple arrangement is schematically presented in Fig. 1.

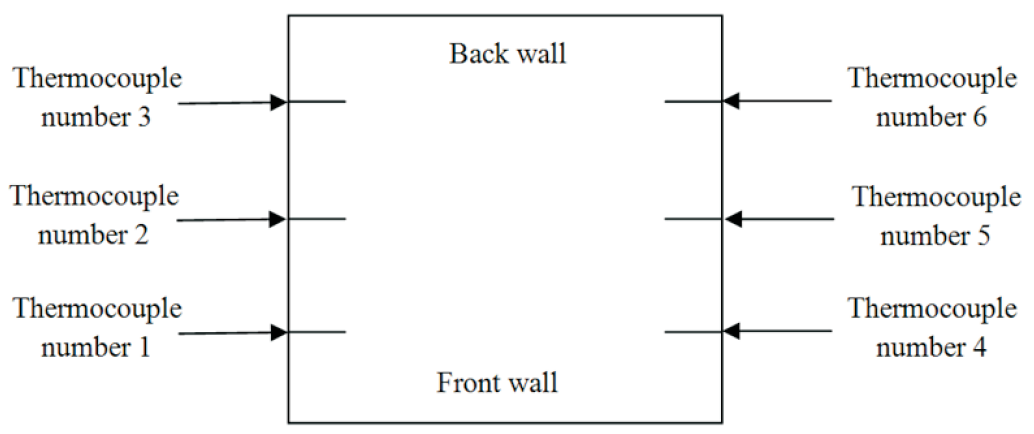

Figure 1: Arrangement of thermocouples on a furnace cross-section. 
Continuous temperature measurement was performed with $\mathrm{NiCr}-\mathrm{NiAl}$ thermocouples in ceramic coating with transducers and recorder. Thermocouples diameters were $10 \mathrm{~mm}$. The thermocouples were installed in application ports in such a way, that their tips were some $0.7 \mathrm{~m}$ from the boiler screen wall. Thermocouple installation and a view from the inside of the furnace are shown in the photographs below (Figs. 2 and 3).

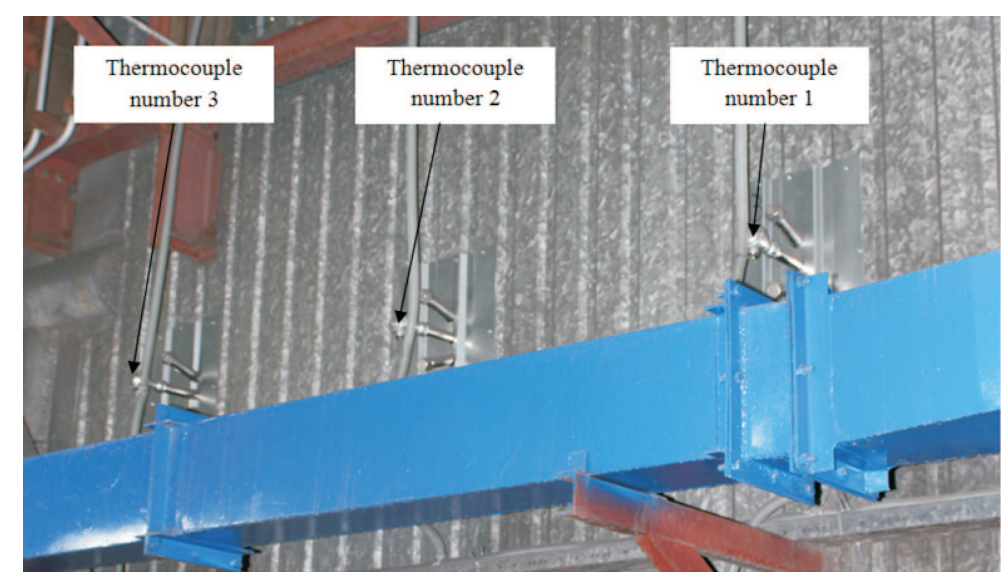

Figure 2: Thermocouple installation on boiler's side wall.

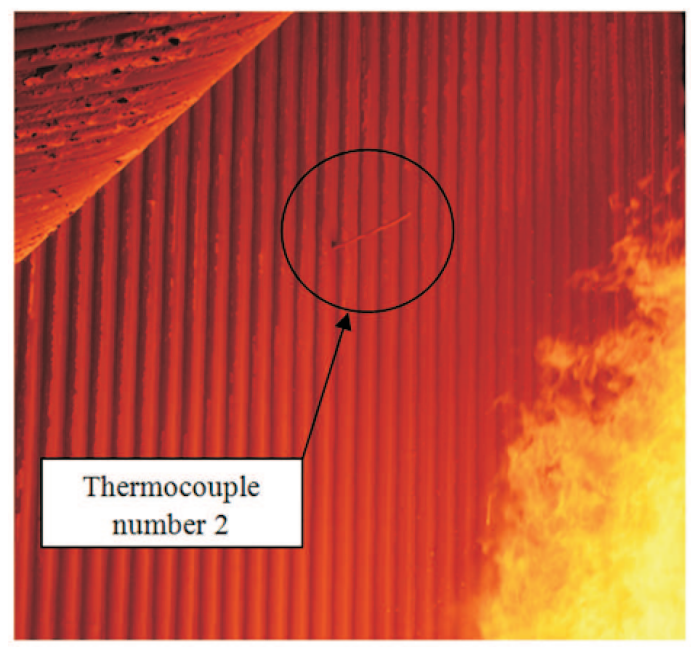

Figure 3: Installed thermocouple seen from the inside of the furnace of investigated boiler. 


\subsection{Temperature measurements with aspirated thermocouple}

As already mentioned, the measurements used to verify validity of those taken with ceramic-coated thermocouples, aimed at estimating method's error attributable to thermal radiation, have been made with an aspirated (suction) thermocouple [12]. Within this method, a thermocouple (NiCr- NiAl) was placed in a contactless manner in a shielding tube with an outer diameter of some $15 \mathrm{~mm}$, so it could be introduced into the furnace through the same application ports. Then the pipe was blanked from the front to ensure better protection against measurement distortion attributable to thermal radiation. The exhaust gas was fed into the tube through large ports spread along its circumference (Fig. 4). The tip of the thermocouple was deeper in the tube than the inlet ports.

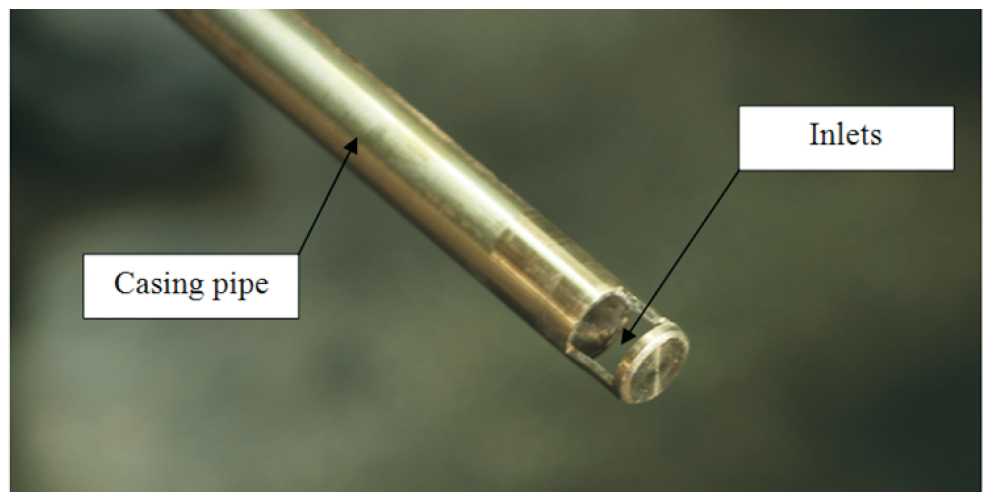

Figure 4: Tip of the aspirated thermocouple designed for the described temperature measurements.

In the described method, the sensor was introduced into the furnace, and then the flue gas was fed into its interior using an external pump. The gas flowing inside the shielding tube at high velocity was flowing over the tip of the thermocouple, which in this arrangement only measured temperature of gas. Unfortunately this method is not as easy and cheap to apply for long-term applications, as the one previously described. For this reason it had been decided to only use it for short periods, in order to estimate errors of the primary method employed. The figure below (Fig. 5) shows the aspirated thermocouple used in the measurements, along with auxiliary components: exhaust gas suction pump, valve for controlling flue gas flow and thermocouple's transducer. 


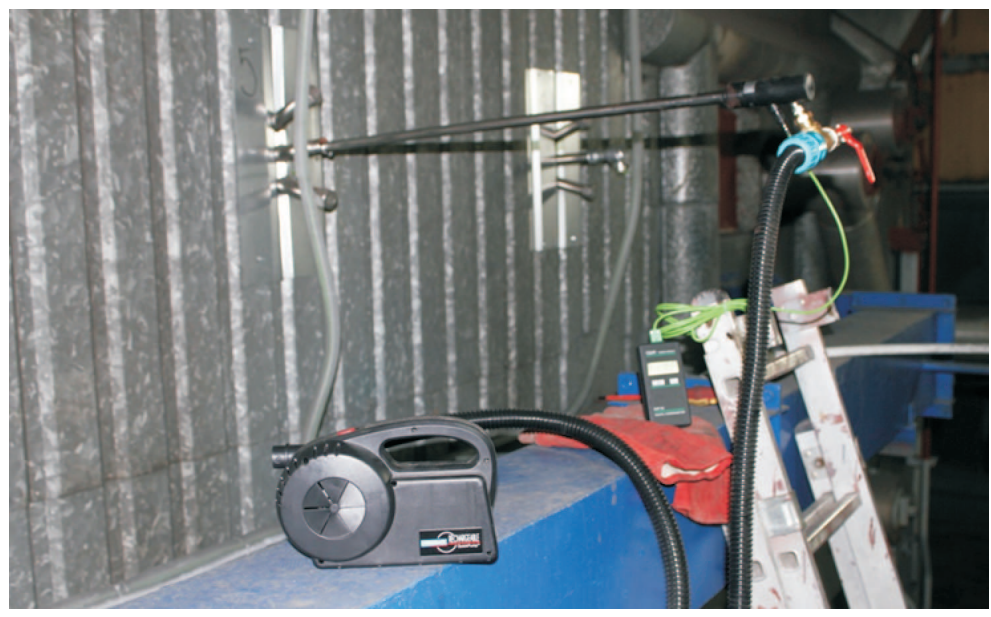

Figure 5: Aspirated thermocouple assembly during a measurement.

\section{Measurement results}

Measurements with a set of six ceramic-coated thermocouples (three per boiler side) were performed in December 2014 (about 2 weeks). During the measurements the boiler was run according to the consumer heat demand. Its output varied considerably during that period: from some $8 \mathrm{MW}$ to almost $25 \mathrm{MW}$. Temperature readings from thermocouples were automated and the results were recorded by a recording device, with a resolution of $12 \mathrm{~min}$. Preliminary analysis of obtained results revealed no considerable differences between the left and right hand side results (average temperature result did not exceed $40^{\circ} \mathrm{C}$ ). In order to facilitate further analytical work, it was therefore decided to average results across thermocouple pairs, i.e.:

- 1 and 4 - first pair,

- 2 and 5 - second pair,

- 3 and 6 - third pair.

Obtained results are shown in Fig. 6, as a function of boiler output.

Analysis of the presented results reveals that the exhaust gas temperature as measured by thermocouples across the furnace, depends on the boiler output and grows along with it. For almost entire range of outputs, the highest - by fair margin - value was recorded by the pair of thermocouples closest to the front wall of the boiler. Values measured by the second 


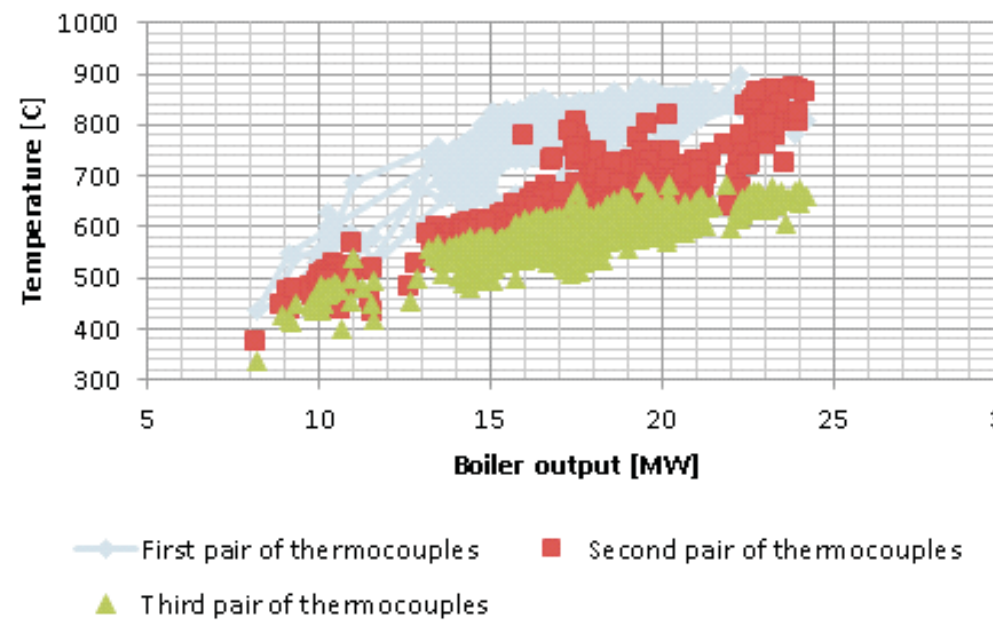

Figure 6: Distribution of the temperatures (averaged as explained in the text) within the furnace. Results of measurements taken with ceramic-coated thermocouples.

and third pair were considerably lower. Temperatures at both those pairs were also quite close to each other within large part of the output range. Only upon exceeding some $22 \mathrm{MW}$ the difference between values measured by those pairs grows, and the temperature recorded by the second pair of thermocouples approaches that from the first pair. In opinion of the authors this proves that the distribution of exhaust gas across the boiler is varying considerably during part-load operation. High temperatures start to extend to the centre of the furnace only for outputs exceeding 22-23 MW.

Collected measurement data was subsequently divided into eight output ranges, from 9 to $25 \mathrm{MW}$. A width of single range was assumed as $2 \mathrm{MW}$. For each range and for each thermocouple pair the measured temperatures were averaged across entire measurement period. Data processed in this way were then plotted (Fig. 7) as a function of chamber length (thermocouple pair index). Data presented in such manner confirms earlier observations. For outputs below $20 \mathrm{MW}$, the highest - by far - value has been recorded by the first pair of thermocouples. Values measured by the second and third pair are much lower and close to each other. Only for output of some 23-25 MW this changes, and values recorded by the second pair approach those from the first pair. Exhaust gas distribution across the furnace becomes more equalised. 


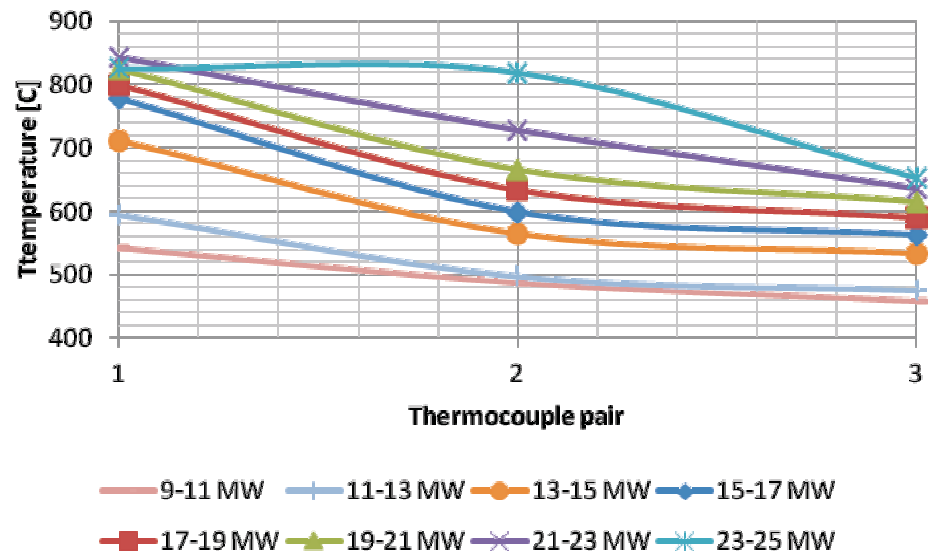

Figure 7: Temperature distribution in the boiler furnace as a function of location for a various boiler output levels - results of measurements with ceramic-coated thermocouples. Data processing and averaging described in the text.

This investigation proves that in case of a grate boiler change of load affects not only the temperature distribution along the height of the furnace, but also along its length. Temperature changes at boiler width are basically negligible.

When the above mentioned measurements were being performed, also verification measurements were made with an aspirated thermocouple for two selected boiler output levels, i.e., 18 and $25 \mathrm{MW}$. Those measurements were taken by introducing a thermocouple through application ports, otherwise used by fixed thermocouples, to the same depth, i.e., some $0.7 \mathrm{~m}$ from the screen wall. The duration of each measurement was from 5 to $8 \mathrm{~min}$ (until constant temperature was reached). Each measurement was repeated three times. The results were then averaged. Results of the measurements are shown in the Tab. 2 below and on a chart (Fig. 8).

It has been revealed that for lower outputs, i.e., lower exhaust gas temperatures, differences between results obtained with both measurement methods are not large. This applies in particular to the measurements made at $18 \mathrm{MW}$ and application ports 5 and 6 , as well as output of $25 \mathrm{MW}$ and application port 6 . The situation is different for high temperatures. Simple and cheap measurement method using ceramic-coated thermocouples yields results lower by some 120 to even $170^{\circ} \mathrm{C}$. This is a considerable difference. In authors' opinion it is caused by thermocouple being cooled in a process 
Table 2: Comparison of results made with fixed thermocouples and the aspirated thermocouple for selected boiler output levels.

\begin{tabular}{|c|c|c|c|c|}
\hline $\begin{array}{c}\text { Thermocouple } \\
\text { application } \\
\text { port index }\end{array}$ & $\begin{array}{c}\text { Fixed } \\
\text { thermocouple }- \\
\text { output 18 MW }\end{array}$ & $\begin{array}{c}\text { Aspirated } \\
\text { thermocouple }- \\
\text { output 18 MW }\end{array}$ & $\begin{array}{c}\text { Fixed } \\
\text { thermocouple }- \\
\text { output 25 MW }\end{array}$ & $\begin{array}{c}\text { Aspirated } \\
\text { thermocouple }- \\
\text { output 25 MW }\end{array}$ \\
\hline \hline 4 & 841 & 1002 & 864 & 1035 \\
\hline 5 & 640 & 650 & 886 & 990 \\
\hline 6 & 610 & 625 & 690 & 720 \\
\hline
\end{tabular}

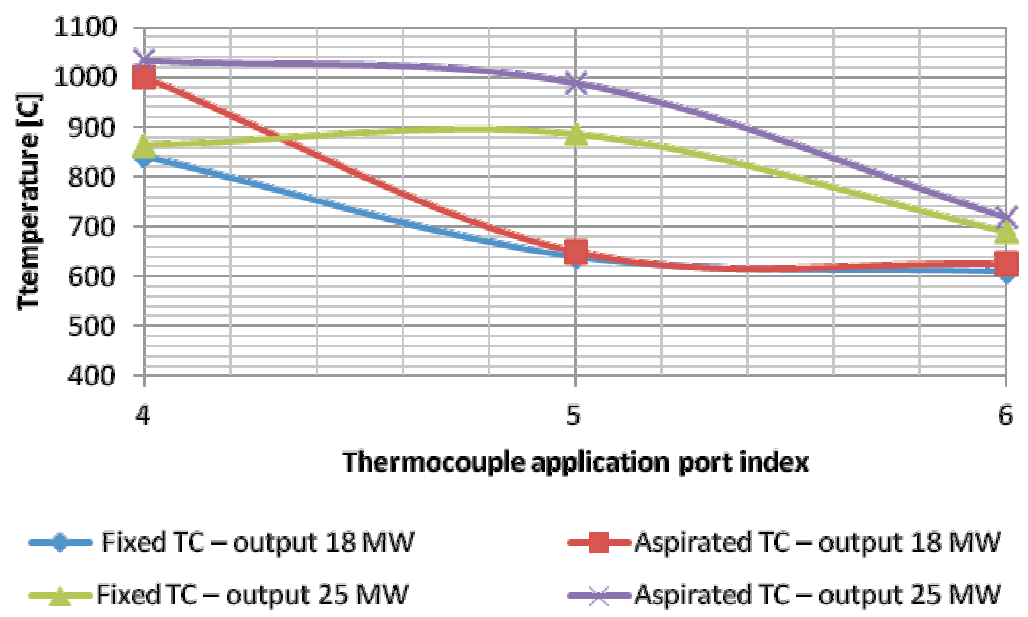

Figure 8: Results of temperature distribution measurements within the furnace made with an aspirated thermocouple.

of radiative heat transfer to boiler water walls. Those differences notwithstanding with the aspirated thermocouple do not change the general conclusion about considerable variability of gas temperature distribution across the investigated plane. Moreover, the verification results reveal that in fact the differences are even greater. The exhaust gas temperature close to the front wall may be even by $350-400^{\circ} \mathrm{C}$ higher than in central and rear zones. 


\section{Conclusion}

Measurement results presented in the paper prove that in case of a grate boiler, changes of boiler load not only affect exhaust gas distribution as a function of furnace height, but also as a function of furnace length. At the same time variability across the width of the furnace is negligible. Results demonstrate that temperature gradient at the investigated cross section is very large, especially for medium and high load. Differences in temperature values may reach even several hundred degrees Celsius across $1 \mathrm{~m}$ of furnace length. Such large gradients cannot have positive influence for example on reducing $\mathrm{NO}_{x}$ emissions. It seems that it would be reasonable to attempt equalising temperature distribution within the furnace of the investigated boiler, for example by using more optimal distribution of primary air below the grate or introduction of the secondary air in a way ensuring induction of more intense turbulences in the exhaust gas flow (e.g., overfire air - OFA or Ecotubes nozzles) $[13,14]$. Such solutions are known and successfully used for example in pulverised bed boilers.

The applied measurement method with ceramic-coated thermocouples fixed within the furnace proved to be reasonably concurrent with the method involving aspirated thermocouple for lower boiler loads and resulting lower gas temperatures. For higher exhaust gas temperatures this cheap and easy method was unduly lowering the results by 120 to even $170^{\circ} \mathrm{C}$ in reference to the results used with aspirated thermocouple, and the latter should be considered more credible, as it almost completely eliminates influence of radiative heat transfer between the thermocouple and other objects. In opinion of the authors observed differences of measured values are attributable to radiative cooling of the fixed thermocouple - by transferring heat to much colder boiler water walls. In their further research, the authors will endeavour to estimate impact of thermal radiation on measured results in a more accurate manner.

Acknowledgements This research is supported by the POIG.01.03.0114-035/12 project which is cofinanced by the European Regional Development Fund under the Operational Programme Innovative Economy. 


\section{References}

[1] KRAWCZyK P., LeWAndowski J.: Usage of national potential of water boilers in the context of EU directives. Industrial Furnaces and Boilers 7-8(2013), 29-33 (in Polish).

[2] Wrzesińska B., Krzywda R., Wąsowski T., Krawczyk P., Badyda K.: A selective non-catalytic reduction of nitrogen oxides technology for application in industrial and municipal heating boilers. Chemical Industry 94(2015), 4, 608-613 DOI: 10.15199/62.2015.4.22 (in Polish).

[3] Ortowski P.: Steam boilers. Design and Calculations. WNT, 1972 (in Polish).

[4] Kordylewski W.: Combustion and Fuels. Wrocław University of Technology Publishers, Wrocław 2005 (in Polish).

[5] Szkarowski A., Janta-Lipińska S.: Automatic quality control of solid fuel combustion in industrial and heating boilers. Mid-Pomeranian Scientific Association of Environment Protection 11(2009), 241-255 (in Polish).

[6] Lozbin V., Wójcik W., Zhelazko G.: Modified acoustic method for determining the temperature in industrial boilers. PAK 53(2007),11, 34-37 (in Polish).

[7] Rinaldi F., Najafi B.: Temperature Measurement in WTE Boilers Using Suction Pyrometers. Sensors 13(2013), 5633-15655, DOI:10.3390/s131115633.

[8] Kychakoff G., Hollingshead, A.F., Boyd S.P.: Use of acoustic temperature measurements in the cement manufacturing pyroprocess. In: Proc. Cement Industry Technical Conf., 2005, Conference Record, 23-33.

[9] Shen G.Q., An L.S., JIANg G.S.: Real-time monitoring on boiler combustion based on acoustic measurement. In: Proc. Power India Conf., 2006, IEEE, 4.

[10] Zhang Hongzhou: Research on. In: Proc. 5th Int. Conf. on Intelligent HumanMachine Systems and Cybernetics (IHMSC), Vol. 1, 29-32, Aug. 26-27, 2013.

[11] Taler J., Taler D., Sobota T., Dzierwa P.: New technique of the local heat flux measurement in combustion chambers of steam boilers. Arch. Thermodyn. 32(2012), 3, 103-116, DOI: 10.2478/v10173-011-0016-2 (accessed on Jan. 2012).

[12] Mieszkowski M.: Thermal and energy measurement. WNT, 1981 (in Polish).

[13] Blasiak W., Yang W. H., Dong W.: Combustion performance improvement of grate fired furnaces using ecotube system. J. Energ. Inst. 79(2006), 2, 67-74.

[14] Kordylewski W., Bulewicz E.: Low-emission combustion techniques in the power industry. Wrocław University of Technology Publishers, Wrocław 2000 (in Polish). 